\title{
POLÍTICAS PÚBLICAS DE DESENVOLVIMENTO REGIONAL SUSTENTÁVEL INTERVENÇÃO GOVERNAMENTAL POR MEIO DE UMA INSTITUIÇÃO FINANCEIRA
}

\author{
Claudemir Ramos \\ Amanda Aparecida Ferreira do Nascimento ${ }^{2}$ \\ Cassio Toshiaki Murakami ${ }^{3}$ \\ Emília Roberta Nunes Figueiredo ${ }^{4}$ \\ Vinícius Branco Varela Lema ${ }^{5}$
}

\section{RESUMO}

No cenário mundial atual em que a consciência do bem comum passa a ser amplamente difundida e demanda por organizações sociais e políticas, procurando incorporar novas formas de produção e consumo com o objetivo de reduzir os danos ambientais inerentes aos "necessários" bens econômicos, é imperativo repensar a redistribuição espacial de geração e distribuição de riquezas, resultando no desenvolvimento econômico regionalizado e sustentável. No bojo das premissas do Desenvolvimento Regional Sustentável (DRS) estão contempladas ações que visam melhorias na qualidade de vida das pessoas, buscando promover a organização

1 Mestre em Economia pela PUC-SP. Pesquisador do Grupo de Pesquisas em Economia Industrial, Trabalho e Tecnologia da PUC-SP (EITT/PUC-SP). Professor da Faculdade 28 de agosto, onde coordena o grupo de pesquisas sobre negócios, economia e gestão.

2 Graduanda em Administração de Empresas pela Faculdade 28 de agosto. Integrante do grupo de pesquisas sobre negócios, economia e gestão.

3 Graduando em Administração de Empresas pela Faculdade 28 de agosto. Integrante do grupo de pesquisas sobre negócios, economia e gestão.

4 Graduanda em Administração de Empresas pela Faculdade 28 de agosto. Integrante do grupo de pesquisas sobre negócios, economia e gestão.

5 Graduando em Administração de Empresas pela Faculdade 28 de agosto. Integrante do grupo de pesquisas sobre negócios, economia e gestão. 
social com liberdade econômica, permitindo que os "pequenos empreendedores" disponham de uma maior facilidade para comercializar seus produtos e serviços, possibilitando, inclusive, que venha obter maior valor agregado, lhes permitindo maior acesso aos bens econômicos. Democratizar o acesso ao crédito, impulsionar o associativismo e o cooperativismo, além de estimular e potencializar os negócios com micro e pequenos empreendedores urbanos e rurais, compreende, mas ações propostas pela metodologia de DRS implementada pelo agente financeiro do governo, através do mecanismo de política pública. Destarte, esta pesquisa se propôs a analisar a nova metodologia de DRS, bem como sua influência na economia local. A metodologia aplicada ao trabalho se ateve a um estudo exploratório, se respaldando em pesquisas científicas e demais literaturas acadêmicas referenciadas, com escopo de investigação, sendo que os resultados obtidos responderam satisfatoriamente à proposta da pesquisa em foco.

Palavras-chave: Políticas públicas; Desenvolvimento; DRS; Trabalho; Renda.

\section{CONSIDERAÇÕES INICIAIS}

Criada por decreto lei em $2003^{6}$ com a proposta de promover a inclusão social por meio da geração de trabalho e renda, a estratégia de Desenvolvimento Regional Sustentável (DRS) tem por objetivo fomentar uma significativa melhoria das condições socioeconômicas regionais. O propósito da política pública de DRS por meio do seu principal agente bancário é alavancar o desenvolvimento sustentável das regiōes onde opera, financiando o capital para projetos articulados e autossustentáveis, que resultem em geração de renda e melhor qualidade de vida para os moradores de comunidades espalhadas por todo o país.

O DRS prevê a democratização do acesso ao crédito e o incentivo ao associativismo e ao cooperativismo. Isto é feito por meio de apoio, de capacitação e de

6 Decreto n. 4.793, de 23 de julho de 2003 em seu art. $1^{\circ}$ : Fica criada a Câmara de Políticas de Integração Nacional e Desenvolvimento Regional, do Conselho de Governo, com a finalidade de formular políticas públicas e diretrizes de integração nacional e desenvolvimento regional, bem assim coordenar e articular as políticas setoriais com impacto regional, com vistas a reduzir as desigualdades inter e intra-regionais. 
financiamento fornecidos pelo agente bancário e seus parceiros. Vale ressaltar que esta metodologia de DRS foi elaborada mediante o contato direto com as cidades brasileiras com o intuito de estimular o desenvolvimento do potencial produtivo de cada região tendo em vista suas características e peculiaridades.

Considerando sua capilaridade no território nacional, o Banco do Brasil foi o instrumento público utilizado, responsável por formular a metodologia DRS de modo a prover capacitação e treinamento para a comunidade e parceiros do projeto, atuando constantemente em conjunto com estes e com as entidades governamentais de cada município, valorizando o conceito da cadeia de valor pela qual os trabalhadores desenvolvem uma macrovisão do processo produtivo, o que lhes permite se antecipar frente as novas demandas do mercado. Dito isto, faz se importante que os resultados dos negócios gerados se mostrem duradouros e autossustentáveis, projetando benefícios possíveis às futuras geraçôes.

Atualmente, esta metodologia estratégica de DRS beneficia mais de 100 atividades por todo o país, apoiando cerca de 6.000 mil planos de negócios e auxiliando mais de um milhão de famílias ${ }^{7}$, possibilitando geração de riqueza para a sociedade e para o governo, além de receita para o próprio banco. $\mathrm{O}$ princípio participativo do DRS promove a redução do analfabetismo, o aumento da capacidade profissional, o acesso à informação em tecnologia, a melhoria da qualidade de vida e a valorização da cultura local.

\section{DESENVOLVIMENTO, SUSTENTABILIDADE E POLÍTICAS PÚBLICAS NUMA BREVE CONTEXTUALIZAÇÃO}

Múltiplas transformações de ordem social, política e econômica, dentre outras, estimularam o aparecimento de novos modelos de relações e instituições e mercados, organizações e sociedades. A intensa mundialização socioeconômica que impera na atualidade, se traduz numa integração internacional da produção e dos mercados e, concomitantemente, de hábitos culturais e sociais, implicando também em exclusão e ampliação do atraso relativo para as nações que não se adaptarem satisfatoriamente no novo contexto de desenvolvimento globalizado.

Em 2010 a estratégia DRS contabilizou 3,8 mil planos de negócio, envolvendo 1,2 milhão de beneficiários em 3,9 mil municípios brasileiros, movimentado $\mathrm{R} \$ 8,9$ bilhões, dos quais cerca de R\$ 5,0 bilhões foram aplicados por meio do Programa Nacional de Fortalecimento da Agricultura Familiar (Pronaf). Disponível em: <http://www45.bb.com.br/docs/ri/ra2010/ port/ra/32.htm>. 
Sintetizando a ideia de que o Desenvolvimento Sustentável ${ }^{8}$ tenha derivado pela evidência do crescente desgaste ambiental em escala global, Kon e Sugahara (2012) defendem sua decorrência pelo aumento da competitividade internacional e da transnacionalização da produção, objetivando conciliar o desenvolvimento econômico em resposta ao apelo da sociedade pela preservação ambiental e melhor distribuição da riqueza, tendo por base O Relatório Nosso Futuro Comum apresentado na Conferência Rio-92 ${ }^{9}$, documento este que registraria formalmente a necessidade de repensar o modelo de crescimento econômico das nações através de um olhar crítico sobre as práticas de produção e consumo, declarando que

Muitos de nós vivemos além dos recursos ecológicos, por exemplo, em nossos padrões de consumo de energia. No mínimo, o desenvolvimento sustentável não deve pôr em risco os sistemas naturais que sustentam a vida na Terra: a atmosfera, as águas, os solos e os seres vivos. Na sua essência, o desenvolvimento sustentável é um processo de mudança no qual a exploração dos recursos, o direcionamento dos investimentos, a orientação do desenvolvimento tecnológico e a mudança institucional estão em harmonia e reforçam o atual e futuro potencial para satisfazer as aspirações e necessidades humanas. (CMMAD, 1991)

Com o objetivo de reorganizar os esforços da sociedade na busca do desenvolvimento sustentável, surge na Rio-92 a Agenda 21 Global, que por sua vez se desdobraria nas Agendas 21 Nacional e 21 Local, objetivando engajar as autoridades locais, seus cidadãos, suas organizações locais e empresas privadas.

Atualizando os compromissos das nações em prol de um programa mundial de desenvolvimento sustentável, chegamos ao plano de ação global (PNUD 2016) que congrega as pessoas, o planeta e a prosperidade intitulado Transformando Nosso Mundo: A Agenda 2030 para o Desenvolvimento Sustentável, na qual estão articulados os 17 Objetivos do Desenvolvimento Sustentável (ODS) integradores, coerentes e mensuráveis, os quais concatenam de forma equilibrada as três dimensões do desenvolvimento sustentável: econômica, social e ambiental.

8 Empregado publicamente pela primeira vez em 1979, num simpósio sobre meio ambiente e desenvolvimento das Nações Unidas, somente em 1987 foi adotado como termo técnico no relatório Our Commom Future, também conhecido como relatório Brundtland.

9 Realizada em junho de 1992 no Rio de Janeiro, a Conferência das Nações Unidas sobre o Meio Ambiente e Desenvolvimento (UNCED) — popularmente conhecida como Eco-92 ou Cúpula da Terra - instituiu um novo olhar sobre como a humanidade deveria encarar sua relação com o planeta, despertando o reconhecimento pela comunidade política internacional de que era preciso conciliar o desenvolvimento econômico e social com a utilização consciente dos recursos da natureza. 
De forma clara e precisa, Milton Santos ressalta a importância de se articular os diversos atores sociais para se construir uma nova forma de crescimento da riqueza de forma não excludente, defendendo que:

(...) Deve-se levar em consideração as estruturas econômicas, como uma manifestação de modelos de crescimento adotados, as estruturas geográficas, isto é, a distribuição da população, da infraestrutura, das atividades, das instituiçōes, assim como de seu contexto, e, finalmente, as estruturas sociais e políticas (...). (SANTOS, 2011, p. 169).

Concluindo sua defesa, Santos (2011, p. 169) acrescenta que "a importância de um indivíduo enquanto produtor e consumidor também depende de sua posição no espaço e varia em função das oportunidades na estrutura espacial".

Com a premissa de uma atuação mais eficiente no que se refere ao conceito de desenvolvimento local, Buarque (2006, p. 67) defende que:

(...) O desenvolvimento local sustentável é o processo de mudança social e elevação das oportunidades da sociedade, compatibilizando, no tempo e espaço, o crescimento e a eficiência econômicos, a conservação ambiental, a qualidade de vida e a equidade social, partindo de um claro compromisso com o futuro e a solidariedade entre geraçōes (...).

No plano das necessárias articulações das partes beneficiadas pelo desejado desenvolvimento, cabe adjetivar o conjunto de ações das empresas socialmente engajadas, caracterizadas por Responsabilidade Social (RS). Corporativa, para o qual Barata (2009, p. 276), insistindo na forte relação entre as premissas do Desenvolvimento Sustentável e da Sustentabilidade Empresarial com o conceito de Responsabilidade Social das empresas diz que:

(...) A empresa com Responsabilidade Social atende a necessidade de manutenção de sua competitividade e rentabilidade por meio da construção de um modelo mais justo, calcado na solidariedade, na ética e na sustentabilidade ecológica (...).

Corroborando o papel social das empresas, Abramovay esclarece que:

O grande desafio para a empresa é que ela seja capaz de medir as consequências de suas ações não só em seu entorno imediato, mas numa perspectiva de longo prazo, em que sejam criadas capacidades para antecipar seus resultados. (...) As escolhas das empresas não envolvem apenas seleção de tecnologias, preços e procedimentos produtivos, mas também a maneira como vão relacionar-se com as dimensões socioambientais daquilo que fazem, ou, em outras palavras, a qualidade de sua inserção social. (ABRAMOVAY, 2009, p. 349).

Do ponto de vista organizacional e potencializador de estratégias territoriais integradoras, o governo tem nas mãos a capacidade de atuar em escalas macro e 
micro, por meio, inclusive, das chamadas Políticas Públicas ${ }^{10}$, que se caracterizam por ações desenvolvidas diretamente ou indiretamente pelo Estado, envolvendo entes públicos e privados, e que visam assegurar determinado direito de cidadania, de forma difusa ou para determinado segmento social, cultural, étnico ou econômico.

Desta forma, ao se orientar pela promoção de políticas públicas para o desenvolvimento econômico e social e com recorte regionalizado, o governo se desperta para seu mais antigo agente bancário, cuja característica de ampla cobertura geográfica nacional bem como por seu nível de proximidade com os diversos atores sociais locais, se apresenta como principal agente indutor para o governo possa implementar sua política com capilaridade regional.

\section{UM AGENTE FINANCEIRO COMO INSTRUMENTO PARA O DRS}

As noçôes do ecologicamente correto, economicamente viável e socialmente justo não são conceitos tão recentes. Laranjeira (1997) nos aponta que, tradicionalmente, as instituiçõos financeiras já operavam em termos de especialização de atividades, organizando-se internamente de forma polarizada, sejam elas por meio de atividades de produção que tendiam a ser organizadas, de forma taylorizada, além de atividades comerciais de intermediação e de gestão financeira. Conforme a autora:

Havia, igualmente, uma definição limitada e estável de produtos (pagamentos, empréstimos e investimentos), o que obrigava os bancos a atenderem a mercados segmentados, atuando de forma complementar entre si (bancos comerciais, de depósitos, de investimentos, caixas econômicas) (LARANJEIRA, 1997, p. 111).

Estas, portanto, têm sido noções que a sociedade tem aprendido a refletir e desenvolver já há alguns anos.

Dentre as formas utilizadas pelo subsetor para enfrentar tais problemas, está a de, juntamente com a ampliação do processo de automação, implementar estratégias de racionalização e de reestruturação dos serviços, expressas, principalmente, pela flexibilização do trabalho e pela diversificação dos produtos (LARANJEIRA, 1997, p. 111).

10 Quanto a este conceito, assumiremos a definição apresentada pela Secretaria de Estado do Meio Ambiente e Recursos Hídricos - SEMA (PR), em seu documento intitulado "O que são Políticas Públicas”, disponível em: <http://www.meioambiente.pr.gov.br/arquivos/File/coea/ pncpr/O_que_sao_PoliticasPublicas.pdf $>$.Outro importante trabalho a considerar é o artigo "Políticas Públicas: uma revisão da literatura", da Profa. Dra. Celina Sousa, disponível no: <http://www.scielo.br/pdf/soc/n16/a03n16>. 
Observando os resultados econômicos obtidos por uma de suas instituições financeiras em princípio dos anos 90, o governo passou a analisar os dados sociais gerados segregados por região atendida pelo banco, identificando nesse estudo uma forma de estabelecer sua política de integração com base no desenvolvimento econômico de forma regionalizada.

No ano de 2004 seria fundada pelo agente bancário uma gerência específica em Brasília, cujo escopo seria trabalhar alguns projetos de desenvolvimento envolvendo agências bancárias dos estados do norte e nordeste. Esses projetos começaram a se frutificar através dos resultados observados. Houve, então, a percepção de que as pessoas realmente estavam tendo uma melhoria em sua qualidade de vida. Segundo Barros (2007, p. 15)

(...) a necessidade de contribuir para o Estado brasileiro na indução e apoio aos processos de DRS provocou mudanças no planejamento estratégico desta Instituição em 2003, sendo alterada sua Missão, Crenças e Estratégia Corporativa, incluindo referências explícitas ao seu papel de fomento do desenvolvimento regional sustentável do país.

Logo, o banco deixou de ser um mero repassador de recursos transformando-se num reconhecido agente de discussão e fomento para o desenvolvimento dentro daquelas comunidades. Sobre esse aspecto podemos nos atentar às considerações de Coelho et al., (2012, p. 5) no que se refere às exigências da atual conjuntura:

Os processos de transformação econômica e social parecem exigir novos modelos de gerenciamento, assim como novos procedimentos, instrumentos e outras formas de ação capazes de criar condições adequadas que auxiliem os gestores a lidar com os desafios da sociedade globalizada. Contudo, a crescente complexidade dos processos locais de tomada de decisão e uma agenda urbana cada vez mais ampla trazem ao debate assuntos como o desenvolvimento econômico local, a geração de renda, a segurança pública e a poluição e deterioração ambiental.

Nas regiōes norte e nordeste do país, as agências envolvidas começaram a receber demandas para um quantitativo maior de projetos atendendo diversas cadeias produtivas, como resultado, o agente bancário resolveu, então, que o ideal seria que essa ação se multiplicasse por todo o país, fundando em 2007 as gerências de Desenvolvimento Regional Sustentável em todos os estados.

A proposta dessas gerências de DRS é a promoção de projetos de geração de desenvolvimento pelo menos um em cada agência do Banco do Brasil, ou seja, onde a instituição estiver presente é significativo que se tenha ao menos a discussão em torno de uma cadeia produtiva para a geração de desenvolvimento. 
A Universidade Corporativa Banco do Brasil traz um informativo sobre o DRS, no qual explicita que:

O DRS é uma forma diferente de fazer negócios. Por isso, podemos dizer que o DRS é uma estratégia negocial. Um jeito que o Banco do Brasil arranjou para impulsionar o desenvolvimento sustentável das regiōes, apoiando atividades produtivas com ganhos para todos. Contribuição do Banco do Brasil para o desenvolvimento sustentável. Com isso ganham as pessoas que moram e trabalham nas comunidades, ganham as demais empresas parceiras e ganha o Banco do Brasil. BB (BB, 2015, p. 5)

Nesta perspectiva, o agente bancário deixa de ser um mero repassador de recursos se propondo a estimular uma discussão em torno da própria formação de cadeia produtiva. Neste caso, o crédito passa a ser mais um dos componentes na busca pelo desenvolvimento. Portanto essa é a ideia do DRS integrando a questão da sustentabilidade: a visão do ambientalmente correto e economicamente viável.

Uma atividade economicamente viável é a que apresenta capacidade de produzir ganhos. Um negócio economicamente viável produz recursos que vão permitir a melhoria das condiçôes de vida dos empreendedores, ou seja, do pessoal envolvido no negócio, aumenta a renda dos trabalhadores e leva mais desenvolvimento para a região (BB, 2015, p. 7).

Além disso, há o foco no socialmente justo que visa respeitar a diversidade cultural, haja vista, que:

(...) quando fazemos negócios, precisamos estar atentos a essa diversidade cultural que as regiōes apresentam, pois o que atende às necessidades de uma região pode não servir para outra. As tradiçōes e costumes de um povo, a convivência com a natureza, seu jeito de superar dificuldades, suas táticas para tirar o sustento da terra, as práticas sociais e atividades aprendidas com os antepassados, tudo deve ser respeitado e aproveitado para desenvolver açōes de DRS. Isso vai ajudar as pessoas a encontrarem soluçōes que tenham a sua "cara" e combinem com a realidade da sua regiâo. (BB, 2015, p. 9)

Vale salientar que outro princípio do DRS é o da participação das partes regionalmente interessadas, procurando fomentar discussóes relacionadas ao que está em curso e o que pode ser potencializado naquela região. Isso possibilita que o agente financeiro seja um importante mediador ao articular parcerias locais. Esta é uma função que o agente financeiro já tem por hábito realizar, só que inserido aí está o ingrediente de uma discussão em torno de uma proposta, de uma cadeia de desenvolvimento produtivo.

Trabalhar baseado na visão de cadeia de valor significa cuidar de todas as etapas do processo produtivo, desde o fornecimento de insumos, passando pela produção, pelo beneficiamento/industrialização, transporte, armazenagem até chegar ao consumidor final do produto (BB, 2015, p. 14). 
Nesta perspectiva, além de potencializar novos negócios a ótica agora está voltada para estabelecer uma metodologia definida em uma estratégia regionalizada. Logo, quando se passa a ter essa metodologia e todas as condições propícias, tais atitudes tomam maior visibilidade fazendo com que as pessoas passem a reconhecer o papel que o agente bancário exerce também como agente de desenvolvimento, desconstruindo a impressão comum de que principal foco de instituição bancária seja "fazer dinheiro". Certamente, de tal modo, ela empresta, financia, viabiliza o capital, mas essa nuance motivadora e agregadora é algo recente no perfil de uma instituição financeira, ainda que privada.

Coelho et al., (2012, p. 4) consideram que o paradigma do desenvolvimento local propõe estratégias de diversificação e de enriquecimento das atividades de um dado território "ao basear-se na mobilização de seus recursos naturais, humanos e econômicos, e de caráter sociopolítico, por oposição ao manejo de um poder central que orienta fluxos de investimento para criar polos de desenvolvimento".

Isso perpassa também por uma adaptação do mercado. $\mathrm{O}$ banco passou a ver o mercado e o modo pelo qual ele estava sinalizando, passou a ter maior preocupação com questóes relacionadas à sustentabilidade e, deste modo, procurou se adaptar às características do novo cenário.

Atualmente pouco se admite uma empresa situada numa comunidade, realizando seu lucro e não promovendo, de alguma forma, o crescimento econômico local. Isto, portanto, é algo pelo qual as instituições estão se despertando e para o sistema bancário não é diferente, comenta Coelho et al., (2002, p. 4):

No que tange à preocupação com a sustentabilidade, o que podemos apreender é que, tornando-se economicamente sustentável, o agente bancário também se tornará sustentável. Neste sentido, o documento do Banco do Brasil explicita que:

Um negócio é sustentável quando explora atividades que buscam o equilíbrio entre as dimensões sociais, econômicas e ambientais e respeitam a identidade cultural das comunidades ou regiōes. Quando o Banco do Brasil decide apoiar atividades que sejam socialmente justas, que vão gerar oportunidades de melhoria de vida para todos, principalmente para a camada mais carente da população, por meio do DRS, ele trabalha para aumentar a inclusão social (BB, 2015, p. 6).

Ainda que uma instituição financeira viva da "bancarização" do crédito, por exemplo, ela depende que a sociedade esteja economicamente viável e equilibrada para conseguir também se manter sustentável. As empresas que apresentam um perfil de 'socialmente responsáveis' vem aumentando sua parcela de participação 
nos mercados em que atuam, conquistado o reconhecimento do consumidor. Já aquelas que não aderiram ao novo cenário vem sofrendo certa resistência.

É importante compreendermos que a sociedade evoluiu neste sentido. Além de contarmos ainda uma discussão que é feita com as empresas sobre a questão do passivo ambiental, sendo este de acordo com Kraemer (2012, p. 2) "contingências formadas em longo período, sendo despercebido às vezes pela administração da própria empresa, envolvendo conhecimento específico".

Passivo Ambiental representa toda e qualquer obrigação de curto e longo prazo, destinadas única e exclusivamente a promover investimentos em prol de açôes relacionadas à extinção ou amenização dos danos causados ao meio ambiente, inclusive percentual do lucro do exercício, com destinação compulsória, direcionado a investimentos na área ambiental (KRAEMER, 2012, p. 2).

As empresas denominadas parcerias, de acordo com o Instituto Ethos (2011) estariam relacionadas a um tipo especial de relação de cooperação entre as partes envolvidas, apoiadas na confiança e na transparência de suas intenções e atos.

Mas há também situações em que as próprias empresas procuram pelo agente bancário, por possuírem determinado passivo ambiental, necessitando, inclusive por força judicial, "aplicá-lo ou devolvê-lo" para a sociedade de alguma forma. Casos, por exemplo, em que possa ter causado um dano ao meio ambiente, tornando-se necessário promoverem um tipo de "reparo" como investimento social. Assim sendo, essas empresas procuram pelo agente financeiro com o intuito de aplicar esse recurso e, por vezes, acabam costurando uma parceria para um novo projeto de desenvolvimento.

\section{$O$ agente financeiro e as etapas para o DRS}

$\mathrm{Na}$ etapa inicial rumo ao DRS a temos conscientização e capacitação do capital humano das agências locais, a chamada "sensibilização" de modo que saibam conduzir o DRS em determinada região. A Cartilha do Banco do Brasil (2015) aponta que momento inicial como o esforço para despertar seus colaboradores quanto as mudanças em curso e para perceberem suas próprias potencialidades.

Ninguém muda se não acreditar que terá benefícios com a mudança, daí a importância desse passo inicial. Não basta, no entanto, estar motivado. É preciso também estar capacitado para a mudança. (BB, 2015, p. 6-10).

Alguns parceiros são também convidados para se capacitarem. Assim, é iniciado o processo. Após esta etapa parte-se para a discussão da definição da atividade, 
sendo que esta faz parte da metodologia. "Depois de motivados e capacitados, é o momento de escolher a atividade produtiva (...). Para a escolha é importante conhecer as vocaçôes locais e analisar o mercado" (BB, 2015, p. 10).

São realizadas discussões e definidas atividades. "É quando são apresentadas opções de negócios e busca de soluções para problemas comuns enfrentados na atividade ou na própria comunidade”. (BB, 2015, p. 10).

O próximo passo se consiste na formação de uma equipe de discussão de DRS, participando dessa equipe as lideranças interessadas em unir as forças em prol daquela cadeia produtiva, conforme esclarece o documento:

Esta equipe deverá ser formada por representantes do banco, do governo, seja ele federal, estadual ou municipal, organizações não governamentais, lideranças, sindicatos, universidades, enfim, todos que atuam na atividade escolhida e outros parceiros que também possam contribuir para o fortalecimento da atividade produtiva. Quanto mais diversificada e participativa for a Equipe DRS, melhores serão os resultados, pois cada um será responsável por ações dentro de sua área de interesse e competência (BB, 2015, p. 11).

A partir daí é feito um diagnóstico dessa cadeia produtiva, sendo que

Essa etapa é muito importante, pois é nela que aumenta o conhecimento da realidade local e da atividade desenvolvida. O diagnóstico possibilita identificar os pontos fortes e os pontos fracos do negócio; as oportunidades e as ameaças que a atividade escolhida pode trazer. Enfim, o diagnóstico é o instrumento que permite pensar sobre a atividade produtiva nos seus aspectos econômicos, sociais, ambientais e culturais (BB, 2015, p. 11).

No âmbito social é discutido o nível de alfabetização, saúde dessas famílias. São discutidas ainda diversas outras questôes que têm por intuito auxiliar no diagnóstico, a fim de buscar açôes em torno de tais questōes. Feito o diagnóstico, passa-se para a elaboração de um plano. "Cabe a todos os participantes proporem os objetivos e as ações necessárias para enfrentar as dificuldades e aproveitar as oportunidades identificadas. Essa fase é muito importante, é o momento da definição de papéis" (BB, 2015, p. 11). Ou seja, este é o momento que o agente bancário, os parceiros e os demais participantes tomam para si uma cota de responsabilidade pelas ações necessárias para atingir meta se manter a sustentabilidade da atividade.

À medida que o diagnóstico aponta que existe, por exemplo, 15\% de analfabetos, o próprio plano de ação do agente bancário já demanda uma ação de alfabetização de jovens e adultos, reafirmando que o diagnóstico tem estreita ligação com o plano de ação. Partindo do plano constituído, é realizada uma análise técnica cuja finalidade é: 
Verificar se as ações que foram planejadas são suficientes para enfrentar os problemas e suprir as necessidades identificadas no diagnóstico da atividade, se os aspectos econômicos, sociais, ambientais (tripé da sustentabilidade) estão sendo observados e se foi respeitada a diversidade cultural (BB, 2015, p. 11).

Caso seja, por exemplo, uma atividade rural, a problemática é encaminhada ao agrônomo do agente bancário a fim de verificar a questão de viabilidade técnica concomitantemente à análise de aderência com a estratégia do negócio e de sua viabilidade econômica, objetivando promover as melhorias e ajustes necessários para se alcançar os resultados satisfatórios deste projeto.

Análises concluídas, o projeto retorna aos técnicos para que assim adentre em sua fase de implementação. "Com tudo definido e todos comprometidos, cada participante executa as ações sob sua responsabilidade. Cada um conforme sua especialidade e sua capacidade, rumo ao objetivo comum” (BB, 2015, p. 11).

Após o projeto implementado, passa-se para a fase de monitoramento e acompanhamento. "Examinar se o planejado está sendo realizado, se os objetivos estão sendo alcançados, se novas ações precisam ser implementadas e se há necessidade de buscar novas parcerias" (BB, 2015, p. 11).

\section{2. $\mathrm{O}$ agente financeiro e a efetividade do DRS nas comunidades}

As comunidades apresentam reação positiva ao serem estimuladas pelo Banco do Brasil e seus parceiros. Vale ressaltar que há um volume significativo de recursos que os parceiros do banco desse projeto têm investido. Para sustentar essa afirmação, apresentamos a tabela informada pelo banco, que nos traz dados relativos ao período entre 2006 e 2010 :

Tabela 1 Estratégia Negocial de Desenvolvimento Regional Sustentável (DRS).

\begin{tabular}{|c|c|c|c|c|}
\hline Período & $\begin{array}{c}\text { Agências } \\
\text { habilitadas }^{(2)}\end{array}$ & $\begin{array}{c}\text { Treinamentos } \\
\text { em DRS }\end{array}$ & $\begin{array}{c}\text { Famílias/Beneficiários } \\
\text { atendidos }^{(4)}\end{array}$ & $\begin{array}{c}\text { Atividades } \\
\text { produtivas }^{(5)}\end{array}$ \\
\hline 2006 & 2.502 & 6.052 & 230.939 & 70 \\
\hline 2007 & 3.998 & 13.507 & 725.450 & 100 \\
\hline 2008 & 4.028 & 14.974 & 1.211 .368 & 100 \\
\hline 2009 & 4.073 & 16.886 & 1.094 .086 & 155 \\
\hline 2010 & 4.176 & 18.507 & 1.167 .997 & 143 \\
\hline
\end{tabular}

(1) Posição Acumulada para o quarto trimestre de cada ano; (2) Agências Habilitadas: são todas as agências/PAA habilitados a operar a estratégia de DRS (Rede Varejo). Para estar habilitada, 
devem estar treinados em DRS o gerente da agência e mais um funcionário; (3) Treinamentos em DRS: é a quantidade de treinamentos realizados pelos funcionários nos cursos corporativos do BB sobre Desenvolvimento Regional Sustentável; (4) Famílias atendidas: quantidade de famílias beneficiadas (PF) por alguma ação constante dos Planos de Negócios DRS em implementação (Rede Varejo). Em 2010, houve mudança de metodologia de famílias atendidas (quantidade de famílias beneficiadas) por beneficiários DRS (pessoas físicas e jurídicas envolvidas diretamente na atividade produtiva apoiada e beneficiadas por açōes do Banco ou dos parceiros nos Planos de Negócios de DRS); (5) Atividades produtivas: são todas as atividades produtivas definidas pelas equipes de trabalho e registradas no aplicativo DRS em Planos de Negócios em implementação. (Disponível em: http://www45.bb.com.br/docs/ri/ra2010/port/ra/32.htm. Acesso em: 27 de abril de 2016).

A os dados da Tabela 1, elaborada e apresentada pelo Banco do Brasil evidenciam que a estratégia de negócios com recorte regionalizado se mostraram positivos, haja vista o quantitativo de atividades produtivas registradas no período apontado. Contudo, além das pessoas e entidades envolvidas diretamente nas atividades produtivas, como os produtores, é preciso considerar também a união de forças com outros setores da sociedade. Neste sentido,

São muitas as possibilidades de parcerias e alianças que a comunidade pode considerar nas ações de DRS: governos, prefeituras, universidades, escolas técnicas, sindicatos, cooperativas, empresas de assistência técnica, associações, organizações não governamentais, empresas de armazenamento, certificadoras, atacadistas, entre muitas outras (BB, 2015, p. 13).

Percebendo que as entidades e organismos sociais estão preocupados em seguir para o mesmo caminho, o agente bancário observa a importância crescente para que sejam fomentadas as tais políticas públicas de DRS, ressaltando, em sua visão, tratar-se de um processo que não haverá retrocesso pois vem sendo construído de forma articulada e consistente. Registra ainda, o quantitativo de empresas e instituições apoiando e inserindo cada vez mais recursos, demonstrando que instituição está no caminho certo, dada sua significativa ampliação.

Concatenando parceiros institucionais, tais como: o Ministério do Desenvolvimento Agrário, a Companhia Nacional de Abastecimento (Conab), o Ministério da Pesca e Aquicultura, o Ministério da Integração, o Banco Nacional de Desenvolvimento Econômico e Social (BNDES), o Banco do Brasil congrega, portanto, diversas entidades que se 'abraçam' em prol da geração de um desenvolvimento autossustentável. Desta forma, sem essas parcerias o agente bancário não conseguiria dar continuidade ao projeto de DRS, declarando que "com união e parcerias, as coisas vão acontecendo. $\mathrm{O}$ trabalho, a organização e a vontade vão transformando as localidades e a vida das pessoas, valorizando a cultura das regióes e preservando a natureza" (BB, 2015, p. 17). 


\section{POLÍTICA PÚBLICA DE CRIAÇÃO DE MERCADO FORMAL POTENCIALIZANDO O DRS}

Com o propósito de promover políticas públicas de geração e distribuição de renda, o governo propiciou a formalização de microempresários através da lei que estabeleceu o Microempreendedor Individual (MEI) ${ }^{11}$, com a finalidade de retirar o cidadão da informalidade e inseri-lo no mercado formal, permitindo seu acesso ao crédito financeiro, inclusive, dentre outros benefícios sociais, contribuindo para o desenvolvimento sustentável. De acordo com o Instituto Ethos,

A empresa é socialmente responsável quando vai além da obrigação de respeitar as leis, pagar impostos e observar as condições adequadas de segurança e saúde para os trabalhadores, e faz isso por acreditar que assim será uma empresa melhor e estará contribuindo para a construção de uma sociedade mais justa (ETHOS, 2011).

Esse é um exemplo da necessidade de articulação da sociedade, das entidades envolvidas com esse público para que ele realmente consiga vir para a formalidade de uma forma sustentável. Precisamos ainda do entendimento por parte da sociedade e das entidades envolvidas com esse público, entendimento de que eles precisam de apoio, que muitas vezes tem de se buscar caminhos menos burocráticos a fim de facilitar que essas pessoas realmente progridam. Portanto, contraditoriamente, ao não pensarmos a lei por si só, mas correlacionada a outras questôes sociais pertinentes, é que iremos tornar as ações viáveis e socialmente justas.

\section{CONSIDERAÇÕES FINAIS}

No cenário mundial atual em que a consciência do bem comum passa a ser amplamente difundida e demanda por organizações sociais e políticas, procurando incorporar novas formas de produção e consumo com o objetivo de reduzir os danos ambientais inerentes aos "necessários" bens econômicos, é imperativo repensar a redistribuição espacial de geração e distribuição de riquezas, resultando no desenvolvimento econômico regionalizado e sustentável.

No bojo das premissas do Desenvolvimento Regional Sustentável (DRS) estão contempladas ações que visam melhorias na qualidade de vida das pessoas, promovendo, inclusive uma organização social com liberdade econômica, permitindo que os "pequenos empreendedores" disponham de uma maior facilidade para comercializar seus produtos e serviços, eliminando, inclusive, a figura do mero

11 Para efeito de base legal, nos apoiaremos na Lei Complementar $n^{\circ} 128$, de 19 de dezembro de 2008. Disponível em: <http://www.planalto.gov.br/ccivil_03/Leis/LCP/Lcp128.htm>. 
atravessador e especulador, possibilitando assim que este empreendedor possa obter maior valor agregado, lhes permitindo maior acesso aos bens econômicos.

No que tange o setor empresarial, na medida em as empresas que se inserem numa determinada comunidade, devem orientar suas estratégias de investimento congregando o bem comum, cumprindo, deste modo, sua função social. Cabe salientar que uma parte significativa dessas empresas já se despertaram para o novo momento na ordem mundial, incorporando em suas estratégias os elementos da Responsabilidade Social e Ambiental.

O mecanismo de política pública para o DRS adotado pelo governo, baseou-se na estratégia criada e implementada pelo seu principal agente bancário. Considerando sua capilaridade no território nacional, o Banco do Brasil foi o instrumento público utilizado, responsável por formular a metodologia DRS de modo a prover capacitação e treinamento para a comunidade e parceiros do projeto, democratizando o acesso ao crédito, impulsionando o associativismo e o cooperativismo, além de estimular e potencializar os negócios com micro e pequenos empreendedores urbanos e rurais, atuando constantemente em conjunto com estes e com as entidades governamentais de cada município, valorizando o conceito da cadeia de valor pela qual os trabalhadores desenvolvem uma macrovisão do processo produtivo, o que pode resultar em negócios gerados que se projetam concatenados e autossustentáveis.

\section{REFERÊNCIAS}

ABRAMOVAY, Ricardo. Responsabilidade Socioambiental: as empresas no meio ambiente, o meio ambiente nas empresas. In: VEIGA, José Eli (Org.). Economia socioambiental. São Paulo: Editora Senac, 2009. p. 335-358.

BARATA, Martha. O Setor Empresarial e a Sustentabilidade no Brasil. In: PÁDUA, José Augusto (Org.). Desenvolvimento, justiça e meio ambiente. Belo Horizonte: Editora UFMG. São Paulo: Peirópolis, 2009. p. 271-295.

BARROS, Ricardo de Farias. Desenvolvimento Regional Sustentável: a experiência do Banco do Brasil. Brasília: Universidade de Brasília, 2007. 201 p. Dissertação (Mestrado em Gestão Social e Trabalho).

BB. Universidade Corporativa Banco do Brasil. DRS. Desenvolvimento Regional Sustentável. 2015. Disponível em: <http://www.bb.com.br/docs/pub/siteEsp/unv/ CartilhaDRS.pdf>. Acesso em: 3 de fev. 2017.

BRASIL. Decreto n. 4.793, de 23 de julho de 2003. Cria a Câmara de Políticas de Integração Nacional e Desenvolvimento Regional, do Conselho de Governo. Disponível em: <http://www.planalto.gov.br/ccivil_03/decreto/2003/d4793.htm>. Acesso em: 22 de jan. 2017. 
BUARQUE, Sérgio C. Construindo o Desenvolvimento Local Sustentável: metodologia de planejamento. 3. ed. Rio de Janeiro: Garamond, 2006.

CMMAD (Comissão Mundial sobre Meio Ambiente e Desenvolvimento). Nosso Futuro Comum. 2. ed. São Paulo: Editora FGV, 1991.

COELHO, L.B.; LORENZETTI, J.V.; CARRION, R.M. A Estratégia de Desenvolvimento Regional Sustentável da Agência do Banco do Brasil de Cantagalo/PR: Limites e Potencialidades. VI ENAPEGS EIXO TEMÁTICO 5: Sustentabilidade, Mercado e Sociedade. Disponível em: <http://anaisenapegs.com.br/2012/dmdocuments/234.pdf>. Acesso em: 12 de março 2017.

ETHOS. Ética e Qualidade nas Relações. 2011. Disponível em: <http://ethos.org.br/ docs/conceitos_praticas/indicadores/responsabilidade/etica.asp $>$. Acesso em: 13 de abril 2017.

KON, Anita; SUGAHARA, Claudemir R.S. Sustentabilidade e Empregos Verdes no Brasil. Curitiba: Appris, 2012.

KRAEMER, Maria Elisabeth Pereira. Passivo Ambiental. Artigo Científico. Disponível em: <http://www.amda.org.br/imgs/up/Artigo_21.pdf.>. Acesso em: $11 \mathrm{de} \mathrm{fev.} 2017$.

LARANGEIRA, Sônia M.G. Reestruturação Produtiva no Setor Bancário: a realidade dos anos 90. Revista Educação \& Sociedade, ano XVIII, n. 61, dezembro/97. Disponível em: <http://www.scielo.br/pdf/es/v18n61/4701.pdf>. Acesso em: 16 de abril 2017.

PNUD (Programa das Nações Unidas para o Desenvolvimento). Transformando Nosso Mundo: a Agenda 2030 para o Desenvolvimento Sustentável. 2016. Disponível em: <http://www.br.undp. org/content/dam/brazil/docs/agenda2030/undp-br-Agenda2030completo-pt-br-2016.pdf>. Acesso em: 21 de mar. 2017.

SANTOS, Milton. Economia Espacial: críticas e alternativas. 2. ed. São Paulo: Edusp, 2011. (Coleção Milton Santos; 3). 